\title{
Efficient Regeneration System for Popular Chili Variety of Bangladesh
}

\author{
Sumaya Parveen and Mohammad Nurul Islam
}

Plant Breeding and Biotechnology Lab, Department of Botany, University of Dhaka, Bangladesh

\begin{abstract}
An efficient and reproducible in vitro regeneration protocol for a popular chili variety Bogurar jhal morich was established. For regeneration of shoots two different explants such as cotyledonary leaf and cotyledonary node were employed using various concentrations and combinations of different growth regulators. MS medium supplemented with $26.0 \mu \mathrm{M}$ BAP was found best for shoot induction from cotyledonary node explants whereas in case of cotyledonary leaf explants, $26.0 \mu M$ BAP and $2.32 \mu M$ Kn hormonal combination produced best results. Cotyledonary node explants also responded best towards multiple shoot induction on MS

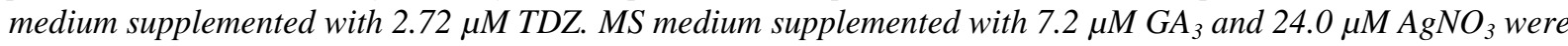
found to be the best media combinations for shoot elongation. Highest percentage of root induction was achieved on MS medium supplemented with 3.0 MM IAA from excised shoots of chili. Following the development of roots in vitro regenerated plantlets were successfully transplanted into soil.
\end{abstract}

Keywords: Chili, regeneration, $B A P, K n, T D Z$

\section{INTRODUCTION}

Chili (Capsicum sp.) belongs to the nightshade family Solanaceae with about 90 genera and around 3000 species (Stern, 2000). The genus Capsicum includes about 25 wild and 5 domesticated species (Adhikery and Amin, 2011). Among all domesticated species, Capsicum annuum $(2 \mathrm{n}=24)$ is distinct with a wide range of varieties from sweet pepper, pungent chili to hot dried powder as a source of vegetable to color in food (Ravishankar et al., 2003). So it has great demand in both green and ripen condition. India is the largest producer and exporter of dried chili pepper in 2012 with the production of $1299940 \mathrm{MT}$ followed by China whereas Bangladesh ranked $4^{\text {th }}$ producing172000MT in 99000 Ha.land area(FAOSTAT). So, it is clear that chili production Bangladesh is hampered due to various reasons.

It is also utilized in the pharmaceuticals, cosmetics and poultry industries. It is used as medicine to treat disorders like dropsy, diarrhoea, asthma, arthritis, muscle cramps and toothache (Vermaet al., 2013). Chili contains amazingly high level of vitamin A and C, minerals such as potassium, magnesium, iron, and manganese and flavonoids like $\beta$-carotene, $\alpha$-carotene, lutein, zeaxanth in and cryptoxanthin etc.

Low germination rate and short span of seed viability are the major limitations associated with conventional cultivation of chili, resulting the increased cost of its cultivation (Ashrafuzzaman et al., 2009). Cross pollination behavior is also a constraint to the propagation of agronomic traits in chili. In addition, various biotic and abiotic factors affect the chili production with reduced quality and yield (Nuezet al., 1996). A number of pests, fungal, bacterial and viral diseases cause huge destructions (Hussain and Abid, 2011). Among the fungal diseases, Anthracnose is the most devastating one, causing losses up to 50\% (Pakdeevarapornet al., 2005). There are about 17 viruses which cause diseases in chili where Chili leaf curl complex is one of the major destructing agents responsible for heavy yield loss up to 53\% and sometimes more (Gunawardena, 2002).

Losses due to pests and diseases can create significant impact the world economy. Pesticides are widely used to control the development of pests and diseases which causes several problems such as health disorders of farmers, detrimental effects on the environment and ecosystem, different diseases of consumer etc. For the improvement of chilicrop, plant tissue culture and genetic engineering can be used as a suitable alternative approach. Despite of its recalcitrant nature, there are several reports on direct and indirect organogenesis and embryogenesis in Capsicum (Agrawal et al., 1989, Ebida and 
Hu, 1993;Gatz and Rogozinska, 1994;Ramírez-Malagón and Ochoa-Alejo, 1996; Berljak, 1999). But the efficiency of most of the protocols greatly differs due to high diversity of existing chili genotypes. Therefore, the investigation was focused on development of an efficient in vitro regeneration system for Bogurer jhal morich, a local farmer popular chili variety.

\section{MATERIAL AND MeTHODS}

The seeds of this variety were collected from the local seed market supplied by "Mithila Seeds" company. The seeds were cleaned from the additional contaminants by washing 3-4 times with distilled water and then treated with $2 \%(\mathrm{v} / \mathrm{v})$ Tween 20 for $5 \mathrm{~min}$. After that seeds were sterilized by immersion in $70 \%$ ethanol for 1 min with vigorous shaking followed by 2 min in $0.1 \%$ Mercuric chloride and finally 5 times rinsing with sterile distilled water.

To generate explants, sterilized seeds were inoculated on $0.8 \%$ (w/v) agar solidified MS (Murashige and Skoog 1962) medium with 3\% (w/v) sucrose for germination and kept in the Dark Till The germination took place and transferred to growth room.

The cotyledonary node and cotyledonary leaf derived from 10-12 days old seedlings were used as sources of explants. Sterilized MS medium supplemented with different hormones andpH adjusted to 5.8, were used for shoot initiation and elongation and root formation.

To develop multiple shoots through direct organogenesis, explants were inoculated in MS medium supplemented with various combinations and concentrations of hormones and additives viz. BAP (6Benzyl aminopurine), IAA (Indole-3 acetic acid), silver nitrate $\left(\mathrm{AgNO}_{3}\right)$ and TDZ (Thidiazuron) for 34 weeks. The cultures were incubated in growth room at $25 \pm 2{ }^{\circ} \mathrm{C}$ and 16 -hours Light and 8 Hours Darkcondition.

The shoot buds initiated from explants were excised and sub-cultured in conical flask containing shoot elongation media for 4-6 weeks. MS medium supplemented with gibberellic acid $\left(\mathrm{GA}_{3}\right)$ and silver nitrate $\left(\mathrm{AgNO}_{3}\right)$ were used as shoot elongation media.

For induction of roots from the base of the elongatedshoots, MS media supplemented with various concentrations of auxins IAA (Indole-3 acetic acid) were used to develop healthy roots. Gelrite was used as solidifying agent for these rooting media. Shoots were cultured in rooting media for 4 weeks.

The completely developed plants were gently removed from rooting media and the roots were washed with autoclaved distilled water to remove the traces of gelrite. Then plantlets were transferred into small plastic pots containing autoclaved soil with plastic covering. These plantlets were regularly watered to maintain adequate humidity. After 2 weeks, plastic covering was removed to reduce humidity. Finally, plantlets were hardened for 4-6 weeks before transplanting into bigger pots under natural condition.

\section{RESUltS}

For multiple shoot induction through direct organogenesis, different concentration and combination of BAP $(18-26 \mu \mathrm{M})$ and $\mathrm{Kn}(0.93-9.28 \mu \mathrm{M})$ were tested using cotyledonary leaf and cotyledonary node explants. Highest number of responsive cotyledonary leaf and cotyledonary node (Figure 1b) explants were $38 \%$ and $96 \%$ on MS medium supplemented with $26 \mu \mathrm{M}$ of BAP within 15-20 days. At 10 days of inoculation the maximum response of cotyledonary leaf was $82 \%$ in MS media containing $26 \mu \mathrm{M}$ BAP and $2.32 \mu \mathrm{M} \mathrm{Kn}$ (Figure $2 b)$. But $\mathrm{Kn}(0.93-9.28 \mu \mathrm{M})$ alone was found to be ineffective towards multiple shoot regeneration.

Media supplemented with different concentration and combination of BAP, IAA, and $\mathrm{AgNO}_{3}$ were used to find out their combined effect on induction of multiple shoots and their development. Only node explants showed positive results with $88 \%$ of shoot induction in MS medium supplemented with IAA and $\mathrm{AgNO}_{3}$.

Different concentrations of TDZ were used in MS medium for multiple shoot regeneration using the explants of cotyledonary leaf and cotyledonarynode. The best hormonal supplement for shoot regeneration was $2.72 \mu \mathrm{M}$ TDZ. Percentage of responsive explants was 60 and 80 from cotyledonary leaf and cotyledonary node explants respectively. The explants responded within 12-25 days. 
Table 1 summarized the data that maximum responses towards shoot initiation from cotyledonary node and cotyledonary leaf explants in MS media supplemented with $26 \mu \mathrm{M}$ BAP and MS media supplemented with $26 \mu \mathrm{M}$ BAP and $2.32 \mu \mathrm{M} \mathrm{Kn}$.
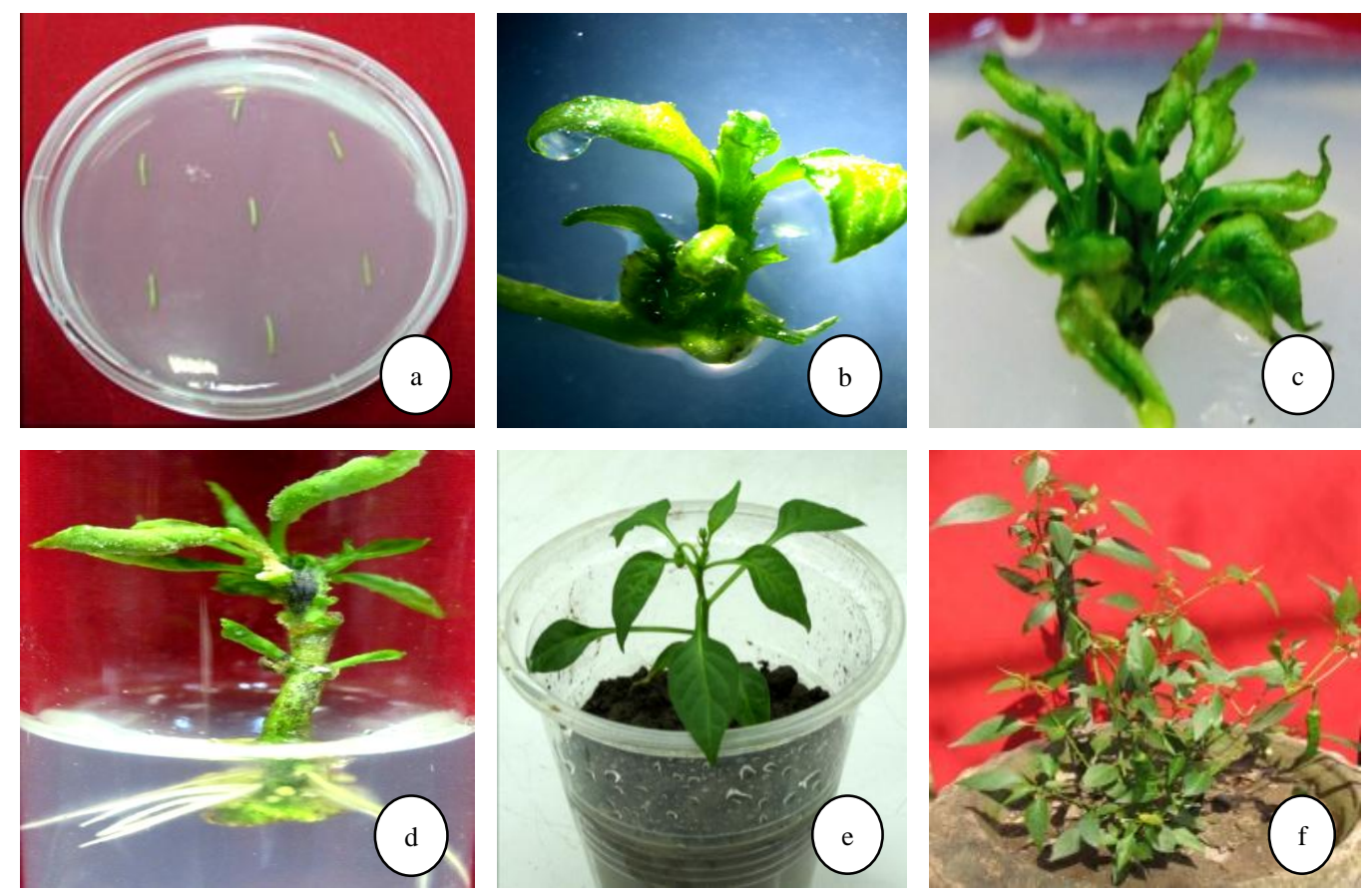

Figure1.Regeneration of Bogurer jhal morich from cotyledonary node explants and subsequent transplantation into soil : (a) Inoculation of cotyledonary node explants on shoot induction media, $(b)$ Multiple shoot initiation on MS medium supplemented with $26 \mu M B A P$, (c) Elongation of multiple shoot on MS

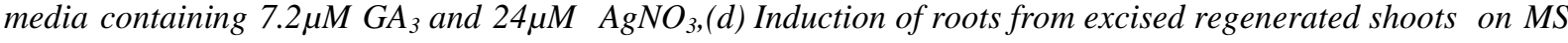
supplemented with $3 \mu M$ IAA, (e) In vitro regenerated plantlets transferred to small Plastic pots containing Soil and (f) Acclimatization of regenerated plants in large clay pots containing soil.

Table1.Effect of various combinations of BAP, Kn, IAA, $\mathrm{AgNO}_{3}$ and $\mathrm{TDZ}$ in MS media on induction and proliferation of shoot bud from the cotyledonary leaf and cotyledonary node explants.

\begin{tabular}{|c|c|c|c|c|c|c|c|c|c|}
\hline \multicolumn{5}{|c|}{$\begin{array}{c}\text { Different combinations of hormones ( } \mu \\
\text { M) }\end{array}$} & \multirow{2}{*}{$\begin{array}{c}\text { No. of } \\
\text { explants } \\
\text { inoculate } \\
\text { d }\end{array}$} & \multicolumn{2}{|c|}{ Cotyledonary leaf } & \multicolumn{2}{|c|}{ Cotyledonary node } \\
\hline $\begin{array}{c}\text { BA } \\
\mathbf{P}\end{array}$ & Kn & $\mathrm{AgNO}_{3}$ & IAA & TDZ & & $\begin{array}{l}\text { Mean no. } \\
\text { of } \\
\text { respondin } \\
\text { g explants }\end{array}$ & $\begin{array}{c}\% \\
\text { respondin } \\
\text { g explants }\end{array}$ & $\begin{array}{l}\text { Mean no. } \\
\text { of } \\
\text { respondin } \\
\text { g explants }\end{array}$ & $\begin{array}{c}\% \\
\text { respondi } \\
\text { ng } \\
\text { explants }\end{array}$ \\
\hline 18 & & & & & 50 & - & - & 20 & 40 \\
\hline 20 & & & & & 50 & - & - & 30 & 60 \\
\hline 22 & & & & & 50 & - & - & 36 & 72 \\
\hline 24 & & & & & 50 & - & - & 41 & 82 \\
\hline 26 & & & & & 50 & 19 & 38 & 48 & 96 \\
\hline 22 & 2.32 & & & & 50 & 12 & 24 & 35 & 70 \\
\hline 24 & 2.32 & & & & 50 & 40 & 80 & 38 & 76 \\
\hline 26 & 2.32 & & & & 50 & 41 & 82 & 20 & 40 \\
\hline 26 & 4.64 & & & & 50 & - & - & 43 & 86 \\
\hline 26 & 4.64 & 17.66 & & & 50 & - & - & 37 & 74 \\
\hline 26 & 4.64 & 20.6 & & & 50 & 10 & 20 & 40 & 80 \\
\hline 26 & 4.64 & 23.55 & & & 50 & 12 & 24 & 42 & 84 \\
\hline 26 & 4.64 & 26.49 & & & 50 & - & - & 42 & 84 \\
\hline 24 & 4.64 & 17.66 & 2.0 & & 30 & - & - & 05 & 16.66 \\
\hline 26 & 4.64 & 17.66 & 2.0 & & 30 & - & - & 14 & 46.66 \\
\hline 20 & & 12 & 2.0 & & 55 & - & - & 49 & 89 \\
\hline \multirow[t]{6}{*}{24} & & 12 & 2.0 & & 55 & - & - & 52 & 95 \\
\hline & & & & 0.9 & 40 & 03 & 07 & 20 & 50 \\
\hline & & & & 1.82 & 40 & 04 & 10 & 38 & 95 \\
\hline & & & & 2.72 & 40 & 24 & 60 & 39 & 97 \\
\hline & & & & 3.63 & 40 & 20 & 50 & 33 & 82 \\
\hline & & & & 4.54 & 40 & 18 & 45 & 30 & 75 \\
\hline
\end{tabular}



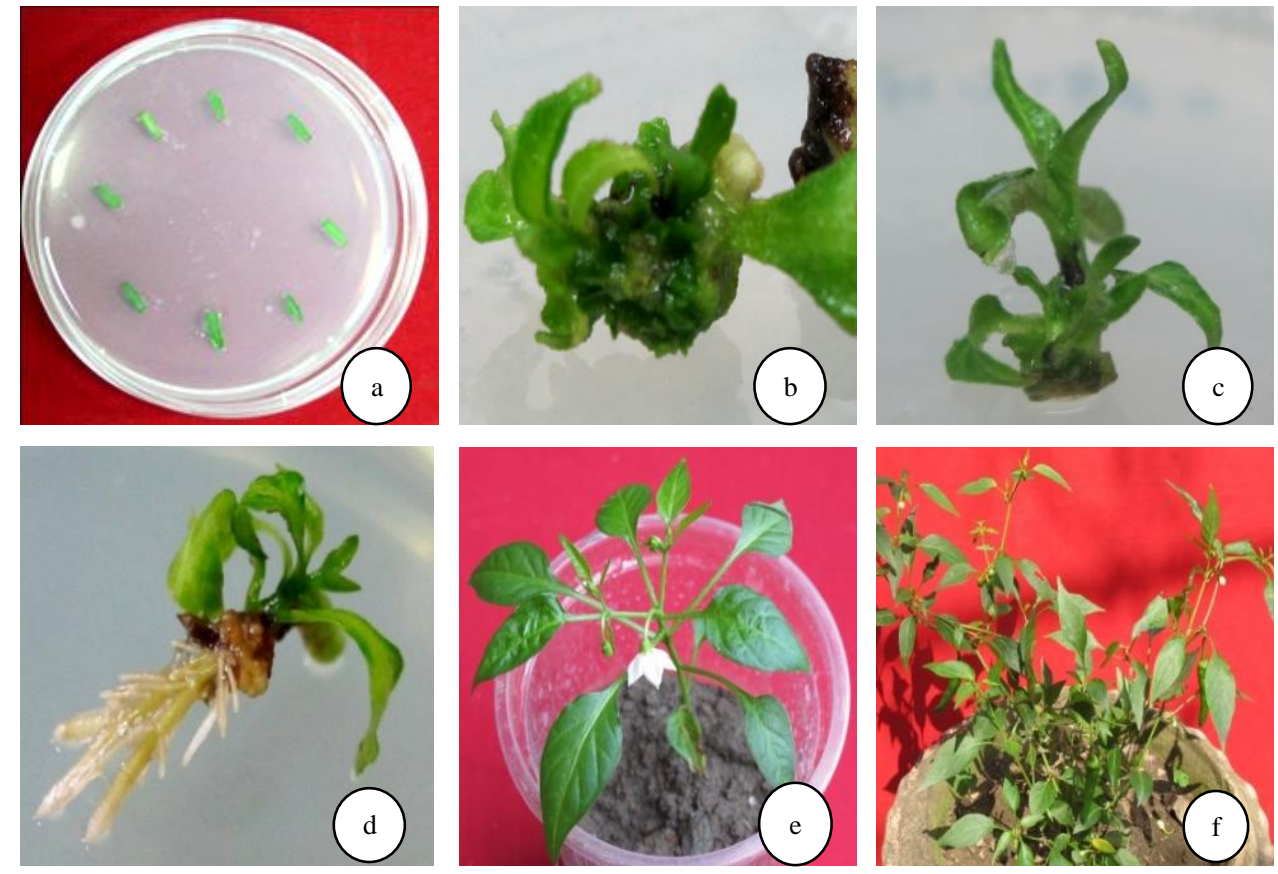

Figure2. Regeneration of Bogurer jhal morich from cotyledonary leaf explants and subsequent transplantation into soil : (a) Inoculation of cotyledonary leaf explants on shoot induction media, (b) Multiple shoot initiation on MS medium supplemented with $26 \mu \mathrm{MBAP}$ and $2.32 \mu \mathrm{M} \mathrm{Kn}$, (c) Elongation of multiple shoot on MS media containing 7.2 $\mu \mathrm{MGA}$ and $24 \mu \mathrm{M} \mathrm{AgNO},(d)$ Induction of roots from excised regenerated shoots on MS supplemented with $3 \mu M I A A,(e)$ In vitro regenerated plantlets transferred to Small Plastic Pots Containing Soiland ( $f$ ) Acclimatization of regenerated plants in large clay pots containing soil.

MS media with or without different hormonal supplements $\left(\mathrm{GA}_{3}, \mathrm{AgNO}_{3}\right)$ were used as shoot elongation medium. MS medium containing $7.2 \mu \mathrm{MGA}_{3}$ and $24 \mu \mathrm{MAgNO}_{3}$ was found as best elongation medium (Figure $1 \mathrm{c} \& 2 \mathrm{c}$ ). It was found that repetition of subculture was required in every 2-3 weeks.

Efficiencies of root formation from in vitro regenerated shoots were tested on rooting media containing different concentration of IAA $(0-4 \mu \mathrm{M})$. Roots initiation was observed on full strength of MS medium without hormonal supplements. The table 2 represents that highest percentages of root producing shoots $(60 \%)$ were obtained on MS medium supplemented with $3 \mu \mathrm{M}$ IAA (Figure 1d \& $2 d)$. Healthy roots produced on this medium within 15-20 days.

Table2. Effect of different concentration of IAA in MS media for root induction from shoots

\begin{tabular}{|c|c|c|c|}
\hline Conc. of IAA $(\boldsymbol{\mu M})$ & No. of shoots & No. of responsive shoots & \% of shoots forming roots \\
\hline- & 25 & 03 & 12 \\
\hline 2.0 & 25 & 08 & 32 \\
\hline 2.5 & 25 & 10 & 40 \\
\hline 3.0 & 25 & 15 & $\mathbf{6 0}$ \\
\hline 3.5 & 25 & 13 & 52 \\
\hline 4.0 & 25 & 12 & 48 \\
\hline
\end{tabular}

The newly developed in vitro plantlets were successfully transplanted into small plastic pots followed by large clay pots containing autoclaved soil (Figure 1e, 1f, 2e \& 2f). The survival rate of plantlets in the larger pots or in the field was found to be $80 \%$. All regenerated plants were normal and able to form fruits similar to those produced by the seed derived plants.

\section{DisCuSSION}

In case ofshoot induction, cytokinin produces hard calluses to multiple shoots in low to high concentration. Although the explants were found to be responsive towards shoot regeneration even at low concentration of BAP $(18 \mu \mathrm{M})$ from cotyledonary node explants used in this study but highest number of responsive cotyledonary leaf and cotyledonary node explants were $38 \%$ and $96 \%$ on MS medium supplemented with $26 \mu \mathrm{M}$ of BAP within 15-20 days. Since, BAP alone was efficient enough to produce shoots from $96 \%$ explants, it can be inferred that this variety of Capsicum annuum has endogenous auxin content and therefore the exogenous supply of cytokinin was able to induce shoot 
buds, this is in accordance with a previous report (Christopher and Rajam, 1994). Healthy and deep green color shoots were obtained from this media combination (Figure 1b). Whereas Kumar et al., 2012 reported regeneration of six different cultivars of Capsicum annuum on MS media supplemented with 4.43-17.75 $\mu \mathrm{M}$ BAP, which indicated the regeneration response canvaried depending on the genotype of the chili plants. The duration required for shoot initiation can be reduced by using the combination of BAP and Kn. At 10 days of inoculation the maximum response of cotyledonary leaf was $82 \%$ in MS media containing hormonal combination of $26 \mu \mathrm{M}$ and $2.32 \mu \mathrm{M} \mathrm{Kn}$ (Figure 2b). But $\mathrm{Kn}(0.93-9.28 \mu \mathrm{M})$ alone were found to be ineffective towards multiple shoot regeneration.

Silver nitrate $\left(\mathrm{AgNO}_{3}\right)$ is one of pepper regeneration affecting factors (Jacobs and Stephens, 1990). It is known as ethylene inhibitors which enhance shoot production (Purnhauseret al., 1987; Chi et al., 1990). $\mathrm{AgNO}_{3}$ is required for shoot regeneration and it is most effective when present in the bud enlargement medium (Hyde and Phillips, 1996). That's why different concentration $\mathrm{AgNO}_{3}$ was used to induce multiple shoots. It was found that $\mathrm{AgNO}_{3}$ reduce the time of shoot elongation. Shoots produced in these media were healthy and bright green in color and leaves elongated and expanded rapidly. But with the increase of $\mathrm{AgNO}_{3}$ concentration, no significant increase of the number of shoot forming explants was found in this variety (Table 1).

Combined effect of BAP, IAA, and $\mathrm{AgNO}_{3}$ on induction of multiple shoots and their development was examined. Only node explants showed single shoot regeneration but cotyledonary leaf and hypocotyl explants formed high number of calluses which did not show response towards shoot regeneration. This result again indicates that this variety contains endogenous auxin content and therefore only hard calluses were found to develop without shoot formation. In contrary to our finding regeneration of multiple shoots from cotyledon, hypocotyl and embryo of Capsicum annuum and Capsicum chenense using different concentration of IAA (1.1-1.7 $\mu \mathrm{M})$, BA (13.3-22.2 $\mu \mathrm{M})$ and $\mathrm{AgNO}_{3}(11.8 \mu \mathrm{M})$ was achieved (Valadez-Bustos et al., 2009). Moreover, several other groups reported shoot regeneration from different explants (node, cotyledonary leaf and hypocotyl segments) using only BA (5-10mg) and IAA (0.3-1.0mg) (Rizwanet al., 2013; Kumar et al., 2011 and Vermaet al., 2013).

Thidiazuron (TDZ) is a substitute of phenyl urea (N-phenyl-1, 2, 3-thidiazol-5-yl urea) and has potentiality to play functions as plant growth regulator which exhibit cytokinin like activity. It has high efficiency in inducing both direct organogenesis and somatic embryogenesis from different explants (Vankataiahet al., 2003; Khan et al., 2006). Maximum shoot regeneration (60\% and 97\% from cotyledonary leaf and cotyledonary noderespectively) was found on MS medium containing $2.72 \mu \mathrm{M}$ TDZ after 2-3 weeks but shoots regenerated on $1.82 \mu \mathrm{M}$ TDZ were much more healthier than the others. Manoharanet al., (1998) observed similar positive effect of TDZ towards shoot induction. But shoot buds induced in medium containing TDZ developed calluses around them and finally turned into black and stunted when cultured long time in the same media or MS medium. From cotyledonary leaf explants, a few thin shoots elongated which also did not survived. But elongation of shoot buds and rooting were obtained on MS medium with 0.5-1.0 mg IAA (Manoharanet al., 1998;Rizwanet al., 2013).

So, MS media supplemented with $26 \mu \mathrm{M}$ BAP and MS media supplemented with $26 \mu \mathrm{M}$ BAP and $2.32 \mu \mathrm{M} \mathrm{Kn}$ were best shoot induction media for cotyledonary node and cotyledonary leaf explantsrespectively. Maximum responses towards shoot initiation from cotyledonary node explants which is in conformity with the findings of Hossain et al., (2004) and Andrzej, (2002).

Cessation of shoot elongation was always observed in shoots induced with any hormonal supplements was solved to some extent using shoot elongation media. Remarkable shoot elongation was noticed when shoots were cultured in media fortified with $7.2 \mu \mathrm{M} \mathrm{GA}_{3}$ and $24 \mu \mathrm{M} \mathrm{AgNO}_{3}$ (Figure 1c \& 2c) whereas Valadez-Bustos et al., (2009) reported chili pepper shoot elongation on MS media with 2.9 $\mu \mathrm{M} \mathrm{GA}_{3}$ and $23.5 \mu \mathrm{M} \mathrm{AgNO}_{3}$.

Induction of healthy roots from regenerated shoots is an essential part for successful development of plantlets during tissue culture. In the present study, development of roots has been tried using MS media with or without IAA. Strong and healthy shoots produced a good number of roots on MS medium without IAA due to having endogenous auxin but maximum response $(60 \%)$ was found on media containing $3 \mu$ MIAA (Figure $1 \mathrm{~d} \& 2 \mathrm{~d}$ ). There was no significant difference in the morphology and patterns of root formation. Manoharanet al., (1998), Vermaet al., (2013) and Rizwanet al., (2013) also achieved root formation using 1.43-5.7 $\mu \mathrm{M}$ IAA on rooting media. 


\section{CONCLUSION}

An efficient, simple and reproducible direct shoot regeneration system for a local chili variety was developed using cotyledonary node and cotyledonary leaf explants where cotyledonary node was found more competent towards shoot induction. This system provides a new opportunity for conducting transformation program with useful candidate genes conferring disease, insect and pest resistance in the chili varieties of Bangladesh.

\section{ACKNOWLEDGEMENT}

Authors are highly thankful to University Grants Commission, Bangladesh for providing financial support through University of Dhaka, Dhaka-1000, Bangladesh and Plant Breeding and Biotechnology Lab, Department of Botany, University of Dhaka for proving research facilities.

\section{REFERENCES}

[1] Adhikery, B. and Amin, MHA. 2003. Performance of cotyledonary explants of chilli and the effect of different hormones on In vitro regeneration. Bangladesh Res. Pub. J., 6:57-64.

[2] Agrawa,l S., Chandra, N. and Kothari, SL. 1989. Plant regeneration in tissue cultures of pepper (Capsicum annuum L. cv. Mathania). Plant Cell Tissue Organ Cult.,16:47-55.

[3] Ashrafuzzaman, M., Hossain, MM., Ismail, MR., Haque, MS., Shahedullah, SM. and Zaman, SU. 2009. Regeneration potential of seedling explants of chilli (Capsicum annuиm). Afr. J. Biotechnol., 8(4):591-596.

[4] Berljak, J. 1999. In vitro plant regeneration from pepper (Capsicum annuum L. cv. Soroksari) seedling explants. Phyton (Austria), 39:289-92.

[5] Chi, GL., Barfield, DG.andSim, GE. 1990. Effect of $\mathrm{AgNO}_{3}$ and aminoethoxyvinnylglycine on In vitro shoot and root organogenesis from seedling explants of recalcitrant Brassica genotypes. Plant Cell Rep., 9:195-198.

[6] Christopher, T. and Rajam, MV. 1994. In vitro clonal propagation of Capsicum species. Plant Cell Tissue Organ Cult., 38:25-29.

[7] Ebida, AIA.andHu, CY. 1993. In vitro morphogenetic responses and plant regeneration from pepper (Capsicum annuum L. cv. Early California Wonder) seedling explant. Plant Cell Rep.,13:107-10.

[8] Gatz, A. and Rogozinska, J. 1994. In vitroorganogenetic potential of cotyledon and leaf explants of Capsicum annuum L. cv. Bryza. Acta Soc. Bot. Pol., 63:255-8.

[9] Gunawardena, KNC. 2002. Assessment of yield loss due to thrips (Thysanoptera: Thripidae) in chilli. Annals of the Sri Lanka Department of Agriculture, 4: 275-80.

[10] Heiser, CB.andSwith, PC. 1953. The cultivated capsicum. Eco. Bot., 1:214-227

[11] Hussain, F. and Abid, M. 2011. Pests and diseases of chilli crop in Pakistan: a review int. J. Biol. Biotech., 8 (2): 325-332.

[12] Hyde, CL. and Phillips, GC. 1996. Silver nitrate promotes shoot development and plant regeneration of chile pepper (Capsicum annuum L.) via organogenesis. In vitro Cell. Dev. Biol. Plant, 32(2):72-80

[13] Jacobs, JL. and Stephen,s CT. 1990. Factors affecting the regeneration of peper(Capsicum annuит L.). Hort. Sci., 25:120.

[14] Khan, H., Siddique, I., and Anis, 2006.Thidiazuron induced somatic embryogenesis and plant regeneration in Capsicum annuum. Biol. Plant.50 (4): 789-792.Kumar OA, Rupavati T and Tata SS (2011). Multiple Shoot Induction and Plant Regeneration from Nodal Explants of Chili Peppers (Capsicum annuum L.) Asian J. Exp. Biol. Sci., 2(3): 517-520.

[15] Kumar, RV., Sharma, VK.,Chattopadhyay, B. and Chakraborty, S. 2012. An improved plant regeneration and Agrobacterium - mediated transformation of red pepper (Capsicum annuиm L.) Physiol. Mol. Biol. Plants, 18(4):357-364.

[16] Manoharan, M., Vidya, CSS. And Sita, GL. 1998. Agrobacterium-mediated genetic transformation in red pepper (Capsicum annuum var. PusaJwala). Plant Sci.,131:77-83.

[17] Nuez, F. and Gil-Ortege, R. 1996.Costa J EI cultivo de pimientos, chiles y ajies. Mundi-Prensa, Mexico D. F. 
[18] Pakdeevaraporn, P., Wasee, S., Taylor, PWJ.andMongkolporn, O. 2005. Inheritance of resistance to anthracnose caused by Colletotrichumcapsici in Capsicum. Plant Breed., 124(2):206-208.

[19] Purnhauser, L., Medgyesy, P. and Czako, M.1987. Stimulation of shoot regeneration in TriticumaestivumL. and NicotianaplumbaginifoliaViv. tissue cultures using the ethylene inhibitor $\mathrm{AgNO}_{3}$. Plant cell Rep., 6:1-4.

[20] Ramírez-Malagón, R. and Ochoa-Alejo, N. 1996. An improved and reliable chilli pepper (Capsicum annuum L.) plant regeneration method. Plant Cell Rep.,16:226-31.

[21] Ravishankar, G A., Suresh, B., Giridhar, P., Rao, S R. and Johnson, TS. 2003. Biotecnological studies on Capsicum for metabolite production and plant improvement. In: DE, Amit Krishna ed.Capsicum;The genus Capsicum.HarwoodAcadimic publishers, UK, pp.96-128.

[22] Rizwan, M., Sharma, R., Soni, P., Gupta, NK.andSingh, G.2013. Regeneration protocol for chilli (Capsicum annuum L.) variety mathania. In. J. Sci. Res., 13(1): 3513-3517.

[23] Stern, KR. 2000. Introductory plant biology, Mac Graw Hill Company Inc. United Sataes of America.Pp 630.

[24] Valadez-Bustos, MG.,Aguado-Santacruz, GA., Carrillo-Castañeda, G., Aguilar-Rincon, VH., Espitia-Rangel, E., Montes-Hernandez, S. and Robledo-Paz, A. 2009. In vitro propagation and agronomic performance of regenerated chilli pepper (Capsicum spp.) plants from commercially important genotypes. In vitro Cell Dev. Biol. Plant, 45:650-8.

[25] Venkataiah, P., Christopher, T. and Subhash, K. 2003.Thidiazuron induced high frequency adventitious shoot formation and plant regeneration in Capsicum annuum L. Plant Biotechnol., 5: $245-25$.

[26] Verma, S., Dhiman, K. and Srivastava, DK. 2013. Agrobacterium- mediated genetic transformation of bell pepper (Capsicum annuum L. cv. California wonder) with GUS and npt-II genes. Int. J. Adv. Biotechnol. Res.,4:397-403. 